\title{
Frações de carboidratos de quatro gramíneas tropicais em diferentes idades de corte e doses de adubação nitrogenada
}

[Carbohydrate fractions of tropical grasses at different cutting ages and under nitrogen fertilization]

\author{
L.T. Henriques ${ }^{1,3}$, J.F. Coelho da Silva ${ }^{2,4}$, E. Detmann ${ }^{1,4}$, H.M. Vasquez ${ }^{2,4}$, O.G. Pereira ${ }^{1,4}$ \\ ${ }^{1}$ Departamento de Zootecnia - UFV - Viçosa, MG \\ ${ }^{2}$ Centro de Ciências e Tecnologias Agropecuárias - UENF \\ Av. Alberto Lamego, 2000 \\ 28013-600 - Campos dos Goytacazes - RJ \\ ${ }^{3}$ Bolsista da CAPES \\ ${ }^{4}$ Bolsista do CNPq
}

\begin{abstract}
RESUMO
Avaliaram-se as frações de carboidratos dos capins setária (Setaria anceps Stapf), hemarthria (Hemarthria altissima [Poir] Stapf. \& Hubbard), angola (Brachiaria purpurascens [Raddi] Henr.) e acroceres (Acroceras macrum Stapf.) adubados com 0, 100, 200, 300 e 400kg de N/ha na forma de sulfato de amônio e colhidos aos 28, 42, 56 e 70 dias de idade. Os cortes foram realizados a $20 \mathrm{~cm}$ do solo para o capim-setária e a $10 \mathrm{~cm}$ para as demais espécies. As frações dos carboidratos das forrageiras foram influenciadas pela idade de corte, observando-se com avanço da idade elevação dos teores de carboidratos não fibrosos, especialmente aos 56 dias de idade para os capins-hemarthria e angola e aos 70 dias para setária e acroceres. Os maiores teores de carboidratos fibrosos foram obtidos aos 42 dias em todas as forrageiras. A inclusão de níveis crescentes de adubação nitrogenada contribuiu para redução dos teores de carboidratos fibrosos da parede celular, porém os carboidratos não fibrosos não apresentaram respostas evidentes quanto à adubação nitrogenada.
\end{abstract}

Palavras-chave: capim-acroceres, capim-angola, capim-hemarthria, capim-setária, composição química

\begin{abstract}
The experiment was carried out to evaluate the levels of $0,100,200,300$ and $400 \mathrm{~kg}$ of nitrogen/ha fertilization and the cutting ages at 28, 42, 56 and 70 days on the carbohydrate fractions of the tropical grasses Setaria (Setaria anceps Stapf), Limpo (Hemarthria altissima [Poir] Stapf. \& Hubbard), California (Brachiaria purpurascens [Raddi] Henr.) and Nilo (Acroceras macrum Stpaf). The cuts were made 20cm upper from the ground for Setaria and $10 \mathrm{~cm}$ for the other species. The fractions of the carbohydrates of the grasses were affected by the age of cut, as the older the forage the higher the non-fibrous carbohydrate content, especially at 56 days for Limpo grass and California grass and at 70 days for Setaria and Nilo grasses. The highest percentages of fibrous carbohydrate were observed at 42 days for all the grasses. The increasing levels of nitrogen fertilization contributed for the reduction of the fibrous carbohydrate percentages of the cellular wall, but no response of non-fibrous carbohydrate was observed in function of the nitrogenous fertilization.
\end{abstract}

Keywords: California grass, Limpo grass, Nilo grass, Setaria grass, chemical composition

Recebido em 18 de julho de 2005

Aceito em 6 de março de 2007

*Autor para correspondência (corresponding author)

E-mail: jcoelho@uenf.br

Apoio: FAPERJ, CAPES e CNPq 


\section{INTRODUÇÃO}

$\mathrm{O}$ processo digestivo nos animais ruminantes apresenta a peculiaridade, diferentemente de não ruminantes, de ser capaz de romper as ligações do tipo $\beta$ entre monômeros glicosídicos na parede celular das plantas, o que é possível em função da intensa atividade enzimática de origem microbiana no rúmen (Beever e Mould, 2000). Assim, uma vez que esses animais são capazes de usufruírem dos substratos energéticos contidos nas forragens, as pastagens no Brasil representam a principal e mais barata fonte de energia para os animais ruminantes, nas quais, cerca de 50 a $80 \%$ da matéria seca é constituída de carboidratos que são a principal fonte de energia para o crescimento dos microrganismos ruminais.

Nutricionalmente, os carboidratos podem ser classificados em carboidratos fibrosos (CF) e não fibrosos (CNF). Segundo Mertens (1996), os CF são representados pela celulose e hemicelulose, descritos como sendo de lenta e às vezes incompleta degradação no trato gastrintestinal (TGI), e os CNF, pelos açúcares solúveis, amido e pectina, que são de rápida e completa digestão no TGI, que mediante de um complexo sistema simbiótico e metabólico representam a principal fonte de energia para o organismo animal.

Diante desse sistema, observa-se, contudo, que a busca por métodos acurados para estimação do desempenho animal, do consumo voluntário e da eficiência na qual os nutrientes são utilizados para mantença e produção, constitui objeto constante de pesquisas científicas. O sistema Cornell (Cornell Net Carboydrate and Protein System (CNCPS) - considera os aspectos digestivos das diferentes fontes de carboidratos e proteínas e como estes influenciam o suprimento de energia e proteína metabolizável para o animal (Sniffen et al., 1992; Russell et al., 1992; Fox et al., 1992).

O sistema nutricional CNCPS foi desenvolvido com o objetivo de avaliar os alimentos minimizando as perdas de nutrientes e buscando a maximização da eficiência de crescimento dos microrganismos ruminais (Van Soest, 1994). Segundo esse sistema, os alimentos são constituídos de proteínas, carboidratos, gorduras, cinzas e água, sendo que as proteínas e carboidratos são subdivididos de acordo com suas características químicas, físicas e de degradação ruminal e digestibilidade pós-ruminal (Sniffen et al., 1992).

A caracterização dos carboidratos pode ser mais um instrumento na avaliação adequada das forrageiras no mundo tropical. Busca-se, dessa forma, melhor avaliar os efeitos resultantes das variações de incidência luminosa, índices pluviométricos, idade e níveis de adubação, entre outros, nas alterações da composição da parede celular e, conseqüentemente, da composição bromatológica das forragens ao longo do ano.

As gramíneas tropicais apresentam respostas a diferentes condições de adubação nitrogenada e intervalos de corte (Silva, 2003). Segundo Corsi (1994), o nutriente mais limitante na produção de forragens é o nitrogênio, que é necessário em maior abundância nas plantas superiores, uma vez que sua concentração no solo, em geral, é baixa, apresenta perda por lixiviação e volatilização, e pode, ainda, segundo Camargos (2002), ser utilizado pelos microrganismos do solo. Contudo, a eficiência de resposta à adubação nitrogenada varia com o potencial genético da gramínea e fatores de solo, clima e manejo.

Este trabalho teve por objetivo avaliar os efeitos de diferentes doses de nitrogênio associadas a diferentes idades de corte, na composição das frações de carboidratos nas gramíneas tropicais: capim-setária (Setaria anceps Stapf.), capimhemarthria (Hemarthria altissima [Poir] Stapf. \& Hubbard), capim-angola (Brachiaria purpurascens [Raddi] Henr.) e capim-acroceres (Acroceras macrum Stapf.), cultivadas na região Norte Fluminense.

\section{MATERIAL E MÉTODOS}

$\mathrm{O}$ experimento foi realizado entre outubro de 2000 e junho de 2001. Utilizaram-se os capins setária, hemarthria, angola e acroceres adubados com $0,100,200,300$ e $400 \mathrm{~kg}$ de $\mathrm{N} / \mathrm{h}$ a na forma de sulfato de amônio, e colhidos aos 28, 42, 56 e 70 dias de idade.

$\mathrm{O}$ experimento foi estabelecido em área de baixada, onde as parcelas mediam $150 \mathrm{~m}^{2}$ com $1,00 \mathrm{~m}$ de espaçamento entre essas, as subparcelas $30 \mathrm{~m}^{2}$ e as subsubparcelas $6 \mathrm{~m}^{2}$. Foi 


\section{Henriques et al.}

realizada adubação de correção do solo antes do plantio das gramíneas, conforme resultado de análise de solo, sendo corrigida a acidez por efeito de calagem. O plantio das gramíneas foi realizado com mudas enraizadas dispostas em sulco, com $0,50 \mathrm{~m}$ de espaçamento entre sulcos e $0,5 \mathrm{~m}$ entre plantas. Nos sulcos efetuou-se adubação de $100 \mathrm{~kg} /$ ha de $\mathrm{P}_{2} \mathrm{O}_{5}$ e $30 \mathrm{~kg}$ de $\mathrm{K}_{2} \mathrm{O}$, na forma de superfosfato simples e cloreto de potássio, respectivamente. Realizaram-se cortes de uniformização a $20 \mathrm{~cm}$ de altura do solo para o capim-setária e a $10 \mathrm{~cm}$ para as demais espécies. Após o corte de uniformização, a cada 14 dias foram aplicados, em cobertura, $20 \%$ da dose total do adubo nitrogenado na forma de sulfato de amônio, nas cinco doses, que corresponderam a $0,100,200,300$ e $400 \mathrm{~kg}$ de N/ha. A adubação potássica, que também foi fracionada da mesma forma, consistiu de $60 \mathrm{~kg}$ de $\mathrm{K}_{2} \mathrm{O} / \mathrm{ha}$. As gramíneas foram irrigadas e os tratos culturais feitos mecanicamente sempre que se fez necessário.

Os cortes para coleta das amostras foram feitos a 20 e $10 \mathrm{~cm}$ do solo para o capim-setária e os demais capins, respectivamente. Após o corte, as amostras foram pré-secas em estufa de ventilação forçada $\left(60 \pm 5^{\circ} \mathrm{C} / 72\right.$ horas $)$ e moídas em moinho de faca com peneira de malha de $1 \mathrm{~mm}$.

Posteriormente, as amostras foram quantificadas quanto aos teores de matéria seca (MS), proteína bruta (PB), extrato etéreo (EE) e matéria mineral (MM), segundo métodos descritos por Silva e Queiroz (2004). As determinações da fibra insolúvel em detergente neutro (FDN) e da fibra insolúvel em detergente ácido (FDA), seguiram os protocolos de Van Soest e Robertson (1985) e Van Soest et al. (1991). Os teores de lignina foram estimados por intermédio do método do ácido sulfúrico (Van Soest e Robertson, 1985). Os carboidratos totais (CT) foram obtidos pela fórmula: $\mathrm{CT}=100-(\mathrm{PB}+\mathrm{EE}+\mathrm{MM})$, os carboidratos não fibrosos (CNF) foram obtidos pela subtração da fibra em detergente neutro corrigida para seu conteúdo de cinzas e proteína (FDNcp) dos CT.

$\mathrm{O}$ experimento foi instalado segundo um delineamento em blocos ao acaso (três blocos), em esquema de parcela subsubdivididas, sendo as gramíneas alocadas às parcelas, a adubação nitrogenada às subparcelas $\mathrm{e}$ as idades às subsubparcelas, segundo o modelo:
$\mathrm{Y}_{\mathrm{ijkl}}=\mu+\mathrm{G}_{\mathrm{i}}+\mathrm{B}_{\mathrm{j}}+\mathrm{e}_{\mathrm{ij}}+\mathrm{N}_{\mathrm{k}}+\mathrm{GN}_{\mathrm{ik}}+\mathrm{E}_{\mathrm{ijk}}+\mathrm{C}_{\mathrm{l}}+$ $\mathrm{GC}_{\mathrm{il}}+\mathrm{NC}_{\mathrm{kl}}+\mathrm{GNC}_{\mathrm{ikl}}+\varepsilon_{\mathrm{ijkl}}$;

em que: $Y_{i j k l}=$ observação geral relativa gramínea $\mathrm{i}$, bloco $\mathrm{j}$, nível de adubação $\mathrm{k}$ e idade 1; $\mu=$ constante geral; $\mathrm{G}_{\mathrm{i}}=$ efeito da gramínea $\mathrm{i}$, sendo $\mathrm{i}=1,2,3$ e $4 ; \mathrm{B}_{\mathrm{j}}=$ efeito do bloco $\mathrm{j}$, sendo $\mathrm{j}=1,2$ e $3 ; \mathrm{e}_{\mathrm{ij}}=$ efeito residual das parcelas; $\mathrm{N}_{\mathrm{k}}$ $=$ efeito do nível de adubação $\mathrm{k}$, sendo $\mathrm{k}=1,2,3$, 4 e 5; $\mathrm{GN}_{\mathrm{ij}}=$ efeito da interação da gramínea i e o nível de adubação $\mathrm{k} ; \mathrm{E}_{\mathrm{ijk}}=$ efeito residual das subparcelas; $\mathrm{C}_{1}=$ efeito da idade de corte 1 , sendo $1=1,2,3$ e $4 ; \mathrm{GC}_{\mathrm{il}}=$ efeito da interação da gramínea $\mathrm{i}$ e a idade de corte $1 ; \mathrm{NC}_{\mathrm{kl}}=$ efeito da interação do nível de adubação $\mathrm{k}$ e a idade de corte $1 ; \mathrm{GNC}_{\mathrm{ikl}}=$ efeito da interação da gramínea i, o nível de adubação $\mathrm{k}$ e a idade de corte $1 ; \varepsilon_{\mathrm{ijk}}$ = erro aleatório, associado a cada observação, pressuposto NID $\left(0 ; \sigma^{2}\right)$.

Após as análises químicas, os resultados foram reduzidos às médias de tratamentos (combinações dos níveis dos fatores alocados às parcelas, subparcelas e subsubparcelas), sendo analisados por intermédio de análise de fatores (factor analysis), empregando-se o método Varimax de rotação e ortogonalização de fatores. Adotaram-se como critérios de seleção de fatores a fração retida da variação total (comunalidade) e as cargas fatoriais (Johnson e Wichern, 1998).

\section{RESULTADOS E DISCUSSÃO}

A composição bromatológica das gramíneas pode ser observada na Tab. 1 .

Os valores médios das frações de carboidratos observados nas gramíneas encontram-se na Tab. 2 e os escores fatoriais na Tab. 3.

Após a redução e avaliação da variação conjunta total das variáveis, optou-se pela adoção de três fatores, os quais englobaram $92,8 \%$ da variação total entre tratamentos. Neste contexto, destacase que o primeiro fator (fator 1) relacionou-se intimamente à variação dos componentes fibrosos da parede celular em função da alta carga fatorial associada aos componentes FDNcp e FDA (Tab. 3). Os fatores 2 e 3 mostraram alta associação com os CNF e a lignina, respectivamente, verificados por suas respectivas cargas fatoriais. 
Tabela 1. Teores médios de matéria seca (MS- \%) e de matéria mineral (MM), extrato etéreo (EE), fibra em detergente neutro (FDN) e proteína bruta (PB), em \% da MS, observados nas gramíneas em função dos diferentes níveis de adubação ( $\mathrm{kg} \mathrm{N} / \mathrm{ha}$ ) e idades de corte (dias)

\begin{tabular}{|c|c|c|c|c|c|c|c|c|c|c|c|c|c|c|c|c|c|c|c|c|c|}
\hline \multirow{2}{*}{ Idade } & \multirow{2}{*}{ Nível } & \multicolumn{5}{|c|}{ Capim-setária } & \multicolumn{5}{|c|}{ Capim-hemarthria } & \multicolumn{5}{|c|}{ Capim-angola } & \multicolumn{5}{|c|}{ Capim-acroceres } \\
\hline & & MS & $\mathrm{MM}$ & $\mathrm{EE}$ & FDN & PB & MS & MM & $\mathrm{EE}$ & FDN & PB & MS & MM & $\mathrm{EE}$ & FDN & $\mathrm{PB}$ & MS & MM & $\mathrm{EE}$ & FDN & PB \\
\hline \multirow{6}{*}{28} & 0 & 12,86 & 14,17 & 3,64 & 61,99 & 13,75 & 15,20 & 12,76 & 2,07 & 63,41 & 13,44 & 14,98 & 13,66 & 1,92 & 65,22 & 16,97 & 22,64 & 10,37 & 1,94 & 71,27 & 16,33 \\
\hline & 100 & 12,17 & 12,00 & 2,94 & 61,43 & 15,02 & 17,13 & 11,11 & 1,58 & 67,09 & 14,30 & 14,16 & 11,87 & 2,63 & 63,17 & 17,56 & 23,85 & 10,09 & 1,77 & 69,15 & 18,34 \\
\hline & 200 & 10,86 & 11,47 & 3,33 & 61,76 & 18,75 & 16,63 & 10,98 & 1,86 & 64,60 & 13,95 & 14,70 & 13,21 & 2,04 & 61,22 & 20,60 & 20,48 & 11,48 & 1,75 & 65,48 & 19,74 \\
\hline & 300 & 11,79 & 11,68 & 2,73 & 58,84 & 21,32 & 13,97 & 11,33 & 1,55 & 62,98 & 15,91 & 14,32 & 11,62 & 2,01 & 60,27 & 21,74 & 19,38 & 8,64 & 2,23 & 66,24 & 18,66 \\
\hline & 400 & 10,72 & 10,61 & 2,84 & 53,96 & 25,24 & 14,75 & 11,28 & 1,79 & 68,03 & 17,09 & 12,25 & 12,22 & 2,15 & 61,57 & 21,28 & 20,65 & 8,57 & 1,73 & 67,79 & 20,40 \\
\hline & Média & 11,68 & 11,99 & 3,10 & 59,60 & 18,82 & 15,54 & 11,49 & 1,77 & 65,22 & 14,94 & 14,08 & 12,52 & 2,15 & 62,29 & 19,63 & 21,40 & 9,83 & 1,88 & 67,99 & 18,69 \\
\hline \multirow{6}{*}{42} & 0 & 17,01 & 9,09 & 2,90 & 71,31 & 10,66 & 17,74 & 8,09 & 1,53 & 73,99 & 9,82 & 17,38 & 11,62 & 1,07 & 71,93 & 10,39 & 25,38 & 7,33 & 0,66 & 77,22 & 12,95 \\
\hline & 100 & 12,62 & 11,11 & 2,03 & 70,45 & 12,13 & 15,31 & 8,76 & 1,86 & 75,65 & 10,09 & 17,48 & 11,87 & 1,61 & 71,06 & 12,58 & 20,22 & 8,38 & 0,74 & 73,88 & 13,92 \\
\hline & 200 & 13,05 & 9,51 & 2,81 & 76,13 & 11,48 & 16,84 & 7,73 & 2,60 & 76,27 & 9,57 & 16,11 & 11,11 & 1,17 & 72,79 & 12,70 & 19,57 & 8,04 & 1,33 & 73,96 & 15,49 \\
\hline & 300 & 14,72 & 9,22 & 3,34 & 71,08 & 17,40 & 18,52 & 8,22 & 1,01 & 74,42 & 11,19 & 18,43 & 12,19 & 0,55 & 74,06 & 13,13 & 21,04 & 8,37 & 2,02 & 69,64 & 15,30 \\
\hline & 400 & 15,87 & 8,94 & 4,42 & 71,09 & 18,17 & 15,12 & 9,37 & 1,46 & 72,16 & 10,68 & 18,41 & 10,46 & 1,29 & 71,54 & 14,09 & 19,68 & 8,67 & 1,42 & 70,42 & 15,70 \\
\hline & Média & 14,65 & 9,57 & 3,10 & 72,01 & 13,97 & 16,71 & 8,43 & 1,69 & 74,50 & 10,27 & 17,56 & 11,45 & 1,14 & 72,28 & 12,58 & 21,18 & 8,16 & 1,23 & 73,02 & 14,67 \\
\hline \multirow{6}{*}{56} & 0 & 14,55 & 11,92 & 1,79 & 66,18 & 10,48 & 15,57 & 11,18 & 0,73 & 69,36 & 10,95 & 17,55 & 12,17 & 1,10 & 63,79 & 13,27 & 20,52 & 9,20 & 2,38 & 65,32 & 13,15 \\
\hline & 100 & 12,82 & 10,99 & 4,06 & 63,67 & 12,08 & 16,33 & 11,76 & 1,04 & 68,46 & 10,27 & 17,18 & 13,56 & 0,84 & 64,30 & 13,95 & 19,42 & 9,95 & 1,65 & 64,47 & 16,45 \\
\hline & 200 & 14,01 & 12,01 & 2,59 & 63,76 & 11,82 & 14,96 & 11,18 & 0,42 & 68,18 & 12,33 & 15,68 & 13,30 & 0,54 & 62,91 & 15,98 & 18,34 & 10,26 & 2,09 & 63,12 & 18,09 \\
\hline & 300 & 11,94 & 10,79 & 1,50 & 64,99 & 16,02 & 16,19 & 10,72 & 0,34 & 65,07 & 10,53 & 16,01 & 12,56 & 1,10 & 63,62 & 15,46 & 20,20 & 9,48 & 2,17 & 66,17 & 18,40 \\
\hline & 400 & 13,07 & 10,81 & 0,91 & 61,06 & 17,08 & 15,70 & 11,40 & 0,71 & 67,12 & 11,75 & 16,50 & 12,85 & 0,59 & 62,03 & 17,64 & 20,58 & 12,31 & 2,45 & 66,32 & 18,09 \\
\hline & Média & 13,28 & 11,30 & 2,17 & 63,93 & 13,50 & 15,75 & 11,25 & 0,65 & 67,64 & 11,17 & 16,58 & 12,89 & 0,83 & 63,33 & 15,26 & 19,81 & 10,24 & 2,15 & 65,08 & 16,84 \\
\hline \multirow{6}{*}{70} & 0 & 14,77 & 11,46 & 1,66 & 66,57 & 10,68 & 14,69 & 9,88 & 1,86 & 69,31 & 10,75 & 17,22 & 10,63 & 0,67 & 65,54 & 12,61 & 18,27 & 9,97 & 2,30 & 65,10 & 12,66 \\
\hline & 100 & 13,98 & 9,39 & 2,63 & 64,84 & 12,49 & 14,59 & 10,54 & 1,21 & 70,46 & 11,84 & 17,03 & 12,90 & 1,47 & 64,49 & 13,59 & 17,66 & 11,31 & 1,54 & 65,40 & 14,59 \\
\hline & 200 & 14,07 & 11,40 & 1,71 & 67,35 & 11,89 & 14,45 & 11,48 & 1,60 & 70,16 & 13,09 & 16,45 & 12,68 & 1,49 & 65,15 & 17,21 & 17,32 & 9,46 & 1,59 & 64,35 & 16,88 \\
\hline & 300 & 13,46 & 9,91 & 2,65 & 64,49 & 17,94 & 15,18 & 10,54 & 1,16 & 70,22 & 12,61 & 17,40 & 12,71 & 0,76 & 64,57 & 16,21 & 16,56 & 10,59 & 1,44 & 66,62 & 16,46 \\
\hline & 400 & 11,95 & 11,77 & 2,77 & 61,52 & 16,87 & 15,03 & 10,49 & 1,45 & 68,39 & 13,22 & 15,97 & 12,68 & 1,48 & 70,59 & 17,70 & 15,27 & 11,81 & 1,41 & 66,71 & 19,06 \\
\hline & Média & 13,65 & 10,79 & 2,28 & 64,95 & 13,97 & 14,79 & 10,59 & 1,46 & 69,71 & 12,30 & 16,81 & 12,32 & 1,17 & 66,07 & 15,46 & 17,02 & 10,63 & 1,66 & 65,64 & 15,93 \\
\hline
\end{tabular}

Os escores fatoriais associados aos componentes fibrosos da parede celular (fator 1) assumiram maiores valores aos 42 dias de idade em todas as gramíneas (Tab. 3; Fig. 1). Esse fator representa as variações nas frações dos carboidratos totais que proporcionam maior fonte de energia para os ruminantes em pastejo, principalmente, a fração potencialmente degradável. Observaram-se, a partir dos 42 dias, reduções dos escores do fator 1, demonstrando que, nessa idade, obtêm-se possivelmente as maiores proporções de carboidratos potencialmente degradáveis (celulose e hemicelulose). Segundo Silva (2003), os mecanismos morfofisiológicos demonstram que à medida que a rebrota avança, o número de perfilhos tende a aumentar, ocorrendo subseqüentemente aumento na relação colmo:lâmina foliar, que é um indicativo da queda do valor nutritivo da planta com elevação do nível de componentes indigeríveis.

A adubação nitrogenada contribuiu para redução dos escores do fator associado à parede celular (fator 1), refletindo o fato de que as maiores concentrações de FDNcp e FDA foram observadas naquelas doses inferiores a $200 \mathrm{~kg}$ de N/ha, com exceção do capim-hemarthria, que apresentou comportamento inverso aos 42 dias, uma vez que os escores do fator 1 aumentaram à medida que se elevou a dose de adubo. Aos 42 dias de idade, o capim-hemarthria apresentou aumento das concentrações de FDA em função da doses de adubação (Tab. 2), o que refletiu na elevação dos escores do fator 1 nessa idade. Segundo Sbrissia (2000), o aumento do suprimento de nutrientes para as plantas ocasiona aumento na taxa de crescimento e mortalidade 


\section{Henriques et al.}

dos perfilhos. A duração média de vida das folhas é variável e dependente da espécie, da disponibilidade de nutriente e manejo, dentre outros fatores de interferência. De acordo com Gonçalves (2002), a longevidade das folhas do capim-marandu, manejado a 10 e $40 \mathrm{~cm}$ do solo, é em média 42,9 dias, e conforme Corsi et al. (1994), a longevidade foliar da Brachiaria brizanta é de 37,1 a 46,9 dias. Possivelmente, com o aumento da taxa de crescimento e senescência dos perfilhos, as gramíneas estudadas apresentaram um efeito de diluição na sua composição de carboidratos em função do aumento da produção de matéria seca ocasionada pelo fornecimento de nitrogênio.

Dentre as gramíneas, a que apresentou maiores escores do fator 1 foi o capim-angola aos 42 dias de idade (Tab. 3, Fig. 2). Segundo Camargos (2002), as diferenças observadas entre gramíneas tropicais podem ser decorrentes de características fenotípicas resultantes de mudanças morfogênicas.

Tabela 2. Teores médios (\% da MS) de carboidratos não fibrosos (CNF), fibra em detergente neutro isenta de cinza e proteína (FDNcp), fibra em detergente ácido (FDA) e lignina, observados nas gramíneas em função dos diferentes níveis de adubação ( $\mathrm{kg} \mathrm{N} / \mathrm{ha}$ ) e idades de corte (dias)

\begin{tabular}{|c|c|c|c|c|c|c|c|c|c|c|c|c|c|c|c|c|c|}
\hline \multirow{2}{*}{ Idade } & \multirow{2}{*}{ Nível } & \multicolumn{4}{|c|}{ Capim-setária } & \multicolumn{4}{|c|}{ Capim-hemarthria } & \multicolumn{4}{|c|}{ Capim-angola } & \multicolumn{4}{|c|}{ Capim-acroceres } \\
\hline & & $\mathrm{CNF}$ & FDNcp & FDA & Lig & $\mathrm{CNF}$ & FDNcp & FDA & Lig & $\mathrm{CNF}$ & FDNcp & FDA & Lig & $\mathrm{CNF}$ & FDNcp & FDA & Lig \\
\hline \multirow{6}{*}{28} & 0 & 11,53 & 56,91 & 32,49 & 9,48 & 18,36 & 53,37 & 33,52 & 8,01 & 11,68 & 55,77 & 30,65 & 9,16 & 8,67 & 62,69 & 32,85 & 10,73 \\
\hline & 100 & 14,46 & 55,57 & 33,37 & 7,43 & 14,06 & 58,95 & 31,77 & 9,87 & 11,12 & 56,82 & 31,41 & 9,53 & 11,26 & 58,53 & 31,48 & 10,77 \\
\hline & 200 & 11,12 & 55,34 & 30,23 & 7,70 & 16,16 & 57,05 & 33,23 & 8,66 & 11,32 & 52,82 & 31,08 & 9,43 & 11,12 & 55,92 & 31,01 & 8,42 \\
\hline & 300 & 12,33 & 51,94 & 29,22 & 8,61 & 16,49 & 54,72 & 32,06 & 8,76 & 13,61 & 51,02 & 30,84 & 11,91 & 12,11 & 58,36 & 30,96 & 7,74 \\
\hline & 400 & 13,77 & 47,54 & 28,98 & 8,59 & 11,99 & 57,86 & 31,59 & 8,84 & 11,76 & 52,60 & 29,72 & 7,65 & 10,82 & 58,49 & 29,92 & 9,53 \\
\hline & Média & 12,64 & 53,46 & 30,86 & 8,36 & 15,41 & 56,39 & 32,43 & 8,83 & 11,90 & 53,81 & 30,74 & 9,54 & 10,80 & 58,80 & 31,24 & 9,44 \\
\hline \multirow{6}{*}{42} & 0 & 10,65 & 66,70 & 36,75 & 9,61 & 14,38 & 66,18 & 31,48 & 10,59 & 10,83 & 66,10 & 38,35 & 11,39 & 9,12 & 69,94 & 35,91 & 7,74 \\
\hline & 100 & 8,84 & 65,89 & 35,85 & 8,86 & 10,01 & 69,27 & 34,76 & 11,14 & 9,25 & 64,70 & 36,82 & 11,30 & 10,68 & 66,29 & 34,32 & 6,21 \\
\hline & 200 & 5,71 & 70,49 & 38,77 & 12,53 & 12,87 & 67,24 & 32,44 & 10,91 & 9,53 & 65,49 & 37,85 & 13,39 & 8,51 & 66,64 & 33,33 & 7,29 \\
\hline & 300 & 4,92 & 65,13 & 36,16 & 8,86 & 13,04 & 66,54 & 34,60 & 10,82 & 7,70 & 66,43 & 35,58 & 11,24 & 12,19 & 62,11 & 33,12 & 7,06 \\
\hline & 400 & 3,69 & 64,78 & 34,65 & 9,17 & 13,46 & 65,04 & 36,07 & 9,90 & 9,62 & 64,54 & 35,16 & 7,93 & 11,41 & 62,80 & 32,52 & 6,68 \\
\hline & Média & 6,76 & 66,60 & 36,44 & 9,81 & 12,75 & 66,85 & 33,87 & 10,67 & 9,39 & 65,45 & 36,75 & 11,05 & 10,38 & 65,56 & 33,84 & 7,00 \\
\hline \multirow{6}{*}{56} & 0 & 14,44 & 61,38 & 33,96 & 5,93 & 15,38 & 61,76 & 34,07 & 7,68 & 15,40 & 58,06 & 33,13 & 6,62 & 15,36 & 59,92 & 33,23 & 7,88 \\
\hline & 100 & 13,71 & 59,17 & 34,86 & 5,59 & 15,21 & 61,71 & 33,36 & 8,28 & 14,36 & 57,29 & 34,59 & 9,11 & 14,31 & 57,64 & 30,74 & 6,61 \\
\hline & 200 & 14,82 & 58,77 & 33,85 & 6,36 & 14,70 & 61,37 & 33,00 & 7,38 & 14,30 & 55,87 & 34,09 & 8,60 & 13,40 & 56,15 & 33,27 & 7,97 \\
\hline & 300 & 11,22 & 60,47 & 33,90 & 6,43 & 19,80 & 58,60 & 32,75 & 8,75 & 13,95 & 56,93 & 35,02 & 9,39 & 12,02 & 57,93 & 31,29 & 7,83 \\
\hline & 400 & 15,11 & 56,09 & 32,56 & 6,22 & 16,09 & 60,05 & 30,91 & 6,44 & 13,95 & 54,97 & 33,03 & 7,94 & 10,77 & 56,38 & 31,27 & 8,41 \\
\hline & Média & 13,86 & 59,18 & 33,83 & 6,11 & 16,24 & 60,70 & 32,82 & 7,71 & 14,39 & 56,62 & 33,97 & 8,33 & 13,17 & 57,60 & 31,96 & 7,74 \\
\hline \multirow{6}{*}{70} & 0 & 14,94 & 61,26 & 38,18 & 8,88 & 14,65 & 62,85 & 33,68 & 7,64 & 17,33 & 58,76 & 33,40 & 7,89 & 14,44 & 60,63 & 34,91 & 7,44 \\
\hline & 100 & 15,40 & 60,10 & 35,52 & 6,33 & 15,70 & 60,71 & 33,07 & 8,66 & 13,98 & 58,06 & 34,08 & 8,40 & 13,54 & 59,02 & 34,27 & 8,25 \\
\hline & 200 & 13,09 & 61,90 & 37,23 & 7,56 & 12,22 & 61,61 & 34,28 & 7,51 & 10,81 & 57,80 & 33,90 & 8,32 & 14,28 & 57,78 & 33,16 & 8,38 \\
\hline & 300 & 9,73 & 59,77 & 32,58 & 6,47 & 11,37 & 64,32 & 33,71 & 7,09 & 11,38 & 58,94 & 34,06 & 8,12 & 12,72 & 58,79 & 33,79 & 8,71 \\
\hline & 400 & 12,02 & 56,57 & 34,59 & 6,63 & 14,53 & 60,32 & 33,67 & 7,57 & 5,07 & 63,07 & 31,81 & 7,51 & 10,01 & 57,71 & 32,27 & 6,98 \\
\hline & Média & 13,04 & 59,92 & 35,62 & 7,17 & 13,69 & 61,96 & 33,68 & 7,69 & 11,71 & 59,33 & 33,45 & 8,05 & 13,00 & 58,79 & 33,68 & 7,95 \\
\hline
\end{tabular}


Frações de carboidratos de quatro gramíneas...

Tabela 3. Escores fatoriais para os fatores associados aos carboidratos que descrevem as gramíneas nos diferentes níveis de adubação ( $\mathrm{kg} \mathrm{N} / \mathrm{ha}$ ) e idades de corte (dias)

\begin{tabular}{|c|c|c|c|c|c|c|c|c|c|c|c|c|c|}
\hline \multirow{2}{*}{ Idade } & \multirow{2}{*}{ Nível } & \multicolumn{3}{|c|}{ Capim-setária } & \multicolumn{3}{|c|}{ Capim-hemarthria } & \multicolumn{3}{|c|}{ Capim-angola } & \multicolumn{3}{|c|}{ Capim-acroceres } \\
\hline & & ${\text { Fator } 1^{\mathrm{a}}}$ & Fator $^{\mathrm{b}}$ & Fator $3^{\mathrm{c}}$ & ${\text { Fator }{ }^{\mathrm{a}}}^{\mathrm{a}}$ & Fator $2^{b}$ & Fator $3^{c}$ & Fator $1^{\mathrm{a}}$ & Fator $^{\mathrm{b}}$ & Fator $3^{\mathrm{c}}$ & Fator $1^{\mathrm{a}}$ & Fator $^{\mathrm{b}}$ & Fator $3^{\mathrm{c}}$ \\
\hline \multirow{6}{*}{28} & 0 & $-0,7680$ & $-0,2375$ & 0,7280 & $-0,3073$ & 2,2171 & 0,0945 & $-1,4553$ & $-0,4297$ & 0,5662 & $-0,2850$ & $-1,2760$ & 1,2794 \\
\hline & 100 & $-0,3191$ & 0,7615 & $-0,4780$ & $-0,6538$ & 0,4513 & 1,0122 & $-1,1547$ & $-0,5214$ & 0,7549 & $-1,0194$ & $-0,4378$ & 1,5195 \\
\hline & 200 & $-1,5779$ & $-0,7719$ & $-0,3915$ & $-0,1813$ & 1,3438 & 0,3402 & $-1,6715$ & $-0,3487$ & 0,8135 & $-1,3096$ & $-0,6281$ & 0,0580 \\
\hline & 300 & $-2,2535$ & $-0,3059$ & 0,3467 & $-0,7955$ & 1,3879 & 0,4897 & $-1,9615$ & 0,6446 & 2,5630 & $-0,9610$ & $-0,4557$ & $-0,4231$ \\
\hline & 400 & $-2,7141$ & 0,3156 & 0,5103 & $-0,8884$ & $-0,3005$ & 0,3025 & $-1,9945$ & $-0,5251$ & $-0,3209$ & $-1,4754$ & $-0,9019$ & 0,7040 \\
\hline & Média & $-1,5665$ & $-0,0476$ & 0,1431 & $-0,5653$ & 1,0199 & 0,4478 & $-1,6475$ & $-0,1501$ & 0,8753 & $-1,0101$ & $-0,7399$ & 0,6276 \\
\hline \multirow{6}{*}{42} & 0 & 1,5964 & $-0,3051$ & 0,4791 & 0,0008 & 0,2812 & 1,2856 & 1,9466 & 0,1454 & 1,6569 & 1,6988 & $-1,2104$ & $-0,8828$ \\
\hline & 100 & 1,1570 & $-1,0630$ & $-0,0435$ & 1,0924 & $-0,7888$ & 1,3924 & 1,2122 & $-0,5512$ & 1,5932 & 0,9858 & $-0,8888$ & $-1,7161$ \\
\hline & 200 & 2,1702 & $-1,5909$ & 2,1004 & 0,3128 & $-0,1030$ & 1,4084 & 1,5134 & $-0,1809$ & 2,9393 & 0,5031 & $-1,6851$ & $-1,0889$ \\
\hline & 300 & 0,9385 & $-2,2955$ & $-0,1546$ & 0,9519 & 0,2841 & 1,3648 & 0,9068 & $-1,3199$ & 1,4581 & 0,1872 & $-0,3232$ & $-0,9836$ \\
\hline & 400 & 0,3187 & $-2,8839$ & 0,0242 & 1,3503 & 0,6240 & 0,8142 & 0,8959 & $-0,9190$ & $-0,5821$ & 0,0442 & $-0,7263$ & $-1,2748$ \\
\hline & Média & 1,2362 & $-1,6277$ & 0,4811 & 0,7416 & 0,0595 & 1,2531 & 1,2950 & $-0,5651$ & 1,4131 & 0,6838 & $-0,9668$ & $-1,1892$ \\
\hline \multirow{6}{*}{56} & 0 & 0,5887 & 0,4897 & $-1,6290$ & 0,6103 & 0,9388 & $-0,4663$ & $-0,0212$ & 0,8780 & $-1,0461$ & 0,1276 & 0,9013 & $-0,2790$ \\
\hline & 100 & 0,6202 & 0,4378 & $-1,8162$ & 0,3269 & 0,8287 & $-0,0752$ & 0,1464 & 0,9632 & 0,5599 & $-0,9040$ & 0,1884 & $-1,0652$ \\
\hline & 200 & 0,2690 & 0,7389 & $-1,2595$ & 0,2006 & 0,5513 & $-0,6684$ & $-0,1385$ & 0,8894 & 0,2684 & $-0,3878$ & 0,4119 & $-0,1772$ \\
\hline & 300 & 0,2450 & $-0,5177$ & $-1,3840$ & 0,0443 & 2,4338 & 0,4787 & 0,2041 & 0,9241 & 0,7372 & $-0,9116$ & $-0,4142$ & $-0,3565$ \\
\hline & 400 & $-0,4086$ & 0,7481 & $-1,2573$ & $-0,4722$ & 0,6964 & $-1,1870$ & $-0,5567$ & 0,6062 & $-0,1430$ & $-1,1968$ & $-0,7269$ & 0,0252 \\
\hline & Média & 0,2629 & 0,3794 & $-1,4692$ & 0,1420 & 1,0898 & $-0,3836$ & $-0,0732$ & 0,8522 & 0,0753 & $-0,6545$ & 0,0721 & $-0,3705$ \\
\hline \multirow{12}{*}{70} & 0 & 1,7818 & 1,4931 & 0,2965 & 0,5594 & 0,5925 & $-0,5464$ & 0,1769 & 1,6302 & $-0,1736$ & 0,7191 & 0,7724 & $-0,6261$ \\
\hline & 100 & 0,9883 & 1,1156 & $-1,3064$ & 0,1314 & 1,0202 & 0,2198 & 0,0863 & 0,6777 & 0,0638 & 0,2335 & 0,5079 & $-0,0776$ \\
\hline & 200 & 1,5156 & 0,6124 & $-0,6413$ & 0,4816 & $-0,0923$ & $-0,6804$ & $-0,1865$ & $-0,4011$ & $-0,0864$ & $-0,2216$ & 0,6558 & 0,0735 \\
\hline & 300 & $-0,3494$ & $-1,1724$ & $-1,3811$ & 0,5632 & $-0,5988$ & $-1,0583$ & 0,0346 & $-0,2494$ & $-0,2316$ & $-0,0252$ & 0,2104 & 0,2043 \\
\hline & 400 & 0,0857 & 0,0203 & $-1,1173$ & 0,2822 & 0,6475 & $-0,5230$ & $-0,5930$ & $-2,8894$ & $-0,9499$ & $-0,6859$ & $-1,0011$ & $-0,9776$ \\
\hline & Média & 0,8044 & 0,4138 & $-0,8299$ & 0,4004 & 0,3138 & $-0,4084$ & $-0,0963$ & $-0,2553$ & $-0,2755$ & 0,0039 & 0,2291 & $-0,2807$ \\
\hline & \multicolumn{8}{|c|}{ Cargas Fatoriais } & \multirow{2}{*}{\multicolumn{5}{|c|}{ Variância explicada por cada fator }} \\
\hline & & & & $\mathrm{CNF}$ & \multicolumn{2}{|c|}{ FDNcp } & FDA & LIG & & & & & \\
\hline & \multicolumn{3}{|c|}{ Fator 1} & $-0,1492$ & \multicolumn{2}{|c|}{0,8257} & 0,9382 & \multicolumn{2}{|l|}{0,1274} & \multicolumn{4}{|c|}{1,6005} \\
\hline & \multicolumn{3}{|c|}{ Fator 2} & 0,9633 & \multicolumn{2}{|c|}{$-0,3946$} & 0,0113 & \multicolumn{2}{|l|}{$-0,1401$} & \multicolumn{4}{|c|}{1,1033} \\
\hline & \multicolumn{3}{|c|}{ Fator 3} & $-0,1454$ & \multicolumn{2}{|c|}{0,0877} & 0,1228 & \multicolumn{2}{|l|}{0,9814} & \multicolumn{4}{|c|}{1,0071} \\
\hline & & munalidade & & 0,9713 & 0,845 & & 0,8954 & 0,9991 & & & 3,7110 & & \\
\hline
\end{tabular}

$\bar{a}=$ fator associado à parede celular $(\mathrm{FDNcp}$ e $\mathrm{FDA}),{ }^{\mathrm{b}}=$ fator associado a $\mathrm{CNF},{ }^{\mathrm{c}}=$ fator associado à lignina.

Foram observados escores fatoriais associados ao fator 2 (fator associado aos CNF) mais elevados aos 56 dias para os capins hemarthria e angola, e aos 70 dias para setária e acroceres, indicando que nestas idades estes capins apresentaram maior concentração de CNF, que representam a porção dos carboidratos totais que fornece energia de rápida utilização para os microrganismos ruminais. Vittori (1998), ao avaliar os capins acroceres e angola em várias idades de corte obteve teores de carboidratos não estruturais, em média, mais elevados aos 56 dias e 42 dias, respectivamente.

O estádio vegetativo das plantas forrageiras apresenta como característica o aumento do número de perfilhos e, conseqüentemente, o número de folhas, enquanto que no estádio reprodutivo, o surgimento de novos perfilhos cessa, e ocorre crescimento dos perfilhos existentes. Segundo Gonçalves (2002), no início do estádio reprodutivo, quando ocorre emissão de inflorescência, a emissão de folhas do perfilho cessa, o que resulta na redução na taxa de emissão de folhas e, conseqüentemente, queda no valor nutritivo do pasto. A produção de matéria seca (PMS) das gramíneas estudadas foi avaliada cocomitantemente por Silva (2003), que obteve maiores índices de PMS no capim-setária, seguidos pelos capins hemarthria, angola e acroceres. Uma vez que, em termos fisiológicos, a mudança de estádio vegetativo ocasiona translocações de nutrientes na planta (Gomide et al., 2002) e fatores como temperatura, luz e água podem acelerar o processo de maturação da planta (Van Soest, 1994), pode-se enfocar que os capins setária e hemarthria, com elevadas PMS, apresentaram queda mais acentuada (entre 28 e 46 dias) nos escores fatoriais associados aos CNF (fator 2) em conseqüência de terem apresentado maturidade antecipada. 
Fator as sociado a parede celular

(Fator 1)

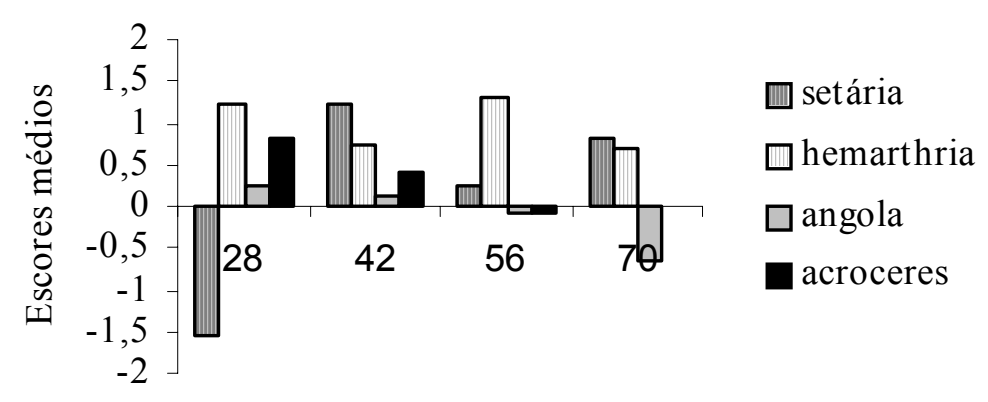

Idades de corte

Figura 1. Comportamento médio (escores fatoriais) do fator associado à parede celular, quando avaliadas as gramíneas nas diferentes idades de corte

\section{Fator associado à CNF}

(Fator 2)

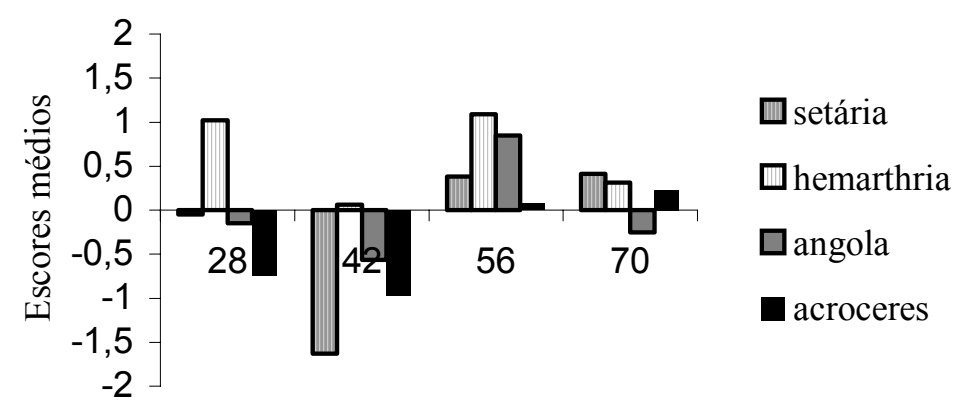

Idades de corte

Figura 2. Comportamento médio (escores fatoriais) do fator associado a CNF, quando avaliadas as gramíneas nas diferentes idades de corte.

De acordo com Mesquita et al. (2002), os teores de CT das forrageiras tropicais podem sofrer alterações devido a aumento na área foliar da planta, pois as folhas reconhecidamente apresentam menores concentrações de frações fibrosas que os colmos. Esses autores, ao avaliarem a composição bromatológica da Brachiaria decumbens sob diferentes condições de manejo, observaram maiores concentrações de
FDN nas plantas que apresentaram grande proporção de perfilhos reprodutivos.

As variações apresentadas pelo fator 2 assumiram padrão inconsistente entre níveis de adubação dentro das idades de corte (Tab. 3). Tal comportamento demonstra pouca influência do teor de nitrogênio no solo sobre os teores de CNF das gramíneas em estudo. Segundo Garcez 
Neto et al. (2002), a aplicação de nitrogênio apresenta grande resposta no período de rebrotação das forrageiras, ou seja, na formação de folhas novas nas forragens já estabelecidas, o que confirma os resultados relatados por Saraiva e Carvalho (1991), que não verificaram efeito de doses de nitrogênio sobre a produção de capimelefante na fase de estabelecimento. Entre as gramíneas estudadas, a que apresentou escores mais elevados do fator 2 foi o capim-hemarthria aos 56 dias de idade. Sua concentração de CNF, no entanto, apresentou pouca variação entre as idades, diferentemente das outras gramíneas, que apresentaram maiores concentrações de CNF a partir dos 56 dias de idade.

A lignina, cuja variação no presente estudo foi associada ao fator 3 (Tab. 3), muito embora não seja classificada quimicamente como um carboidrato, está intrinsecamente ligada aos componentes da parede celular, e pode ser considerada como indisponível tanto no rúmen como nos intestinos (Sniffen et al., 1992). A porcentagem de lignina apresentou tendência de redução à medida que houve decréscimo dos carboidratos totais, tendo-se como referência os CNF e a FDNcp (Tab. 2). Contudo, de maneira geral, os escores do Fator 3 apresentaram-se mais elevados nas idades de 28 dias para o capimacroceres e 42 dias de idade para os demais capins. O capim-setária, por sua vez, demonstrou forte queda nos escores associados ao Fator 3 aos 56 dias de idade (Tab. 3; Fig. 3). De forma geral, observou-se influência inconsistente das doses de nitrogênio sobre os escores fatoriais. Resultados semelhantes foram relatados por Silva (2003), em trabalho paralelo, ao avaliar essas mesmas gramíneas quanto às suas características morfogênicas e de produção, observando ele ausência de resposta dos teores de lignina aos intervalos de corte e adubação nitrogenada.

\section{Fator associado a lignina}

(Fator 3)

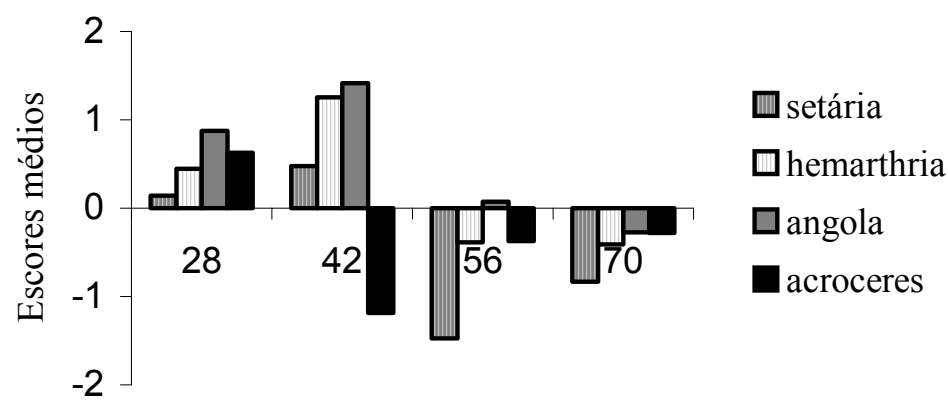

Idades de corte

Figura 3. Comportamento médio (escores fatoriais) do fator associado à lignina, quando avaliadas as gramíneas nas diferentes idades de corte.

Fatores ambientais, tais como intensidade luminosa e temperatura, influem diretamente na qualidade da forragem. Segundo Van Soest (1994), temperatura, luz e maturidade apresentam efeitos distintos nos constituintes insolúveis em detergente ácido da planta, e esses efeitos interagem de acordo com a estação do ano. A temperatura muitas vezes é fator limitante ao crescimento das folhas afetando principalmente a fotossíntese. Camargos (2002) relatou que, de modo geral, plantas submetidas a baixa temperatura e a dias curtos, apresentam inibição da enzima nitrato-redutase, que catalisa a conversão do nitrato absorvido pelas raízes, a nitrito, que, posteriormente, na forma de amônia, servirá de substrato para síntese de aminoácidos, que, por sua vez, resultarão em expansão da parte aérea da planta. 


\section{Henriques et al.}

No presente experimento, as idades de corte de 56 dias e 70 dias foram realizadas em meados de maio e no início de junho, respectivamente, época em que foi registrada a temperatura média mais baixa do período experimental $\left(15^{\circ} \mathrm{C}\right)$ (Fig. 4). Assim, as oscilações observadas nos teores de lignina, nessas condições, podem ter sido conseqüência de variações ambientais não controladas experimentalmente.

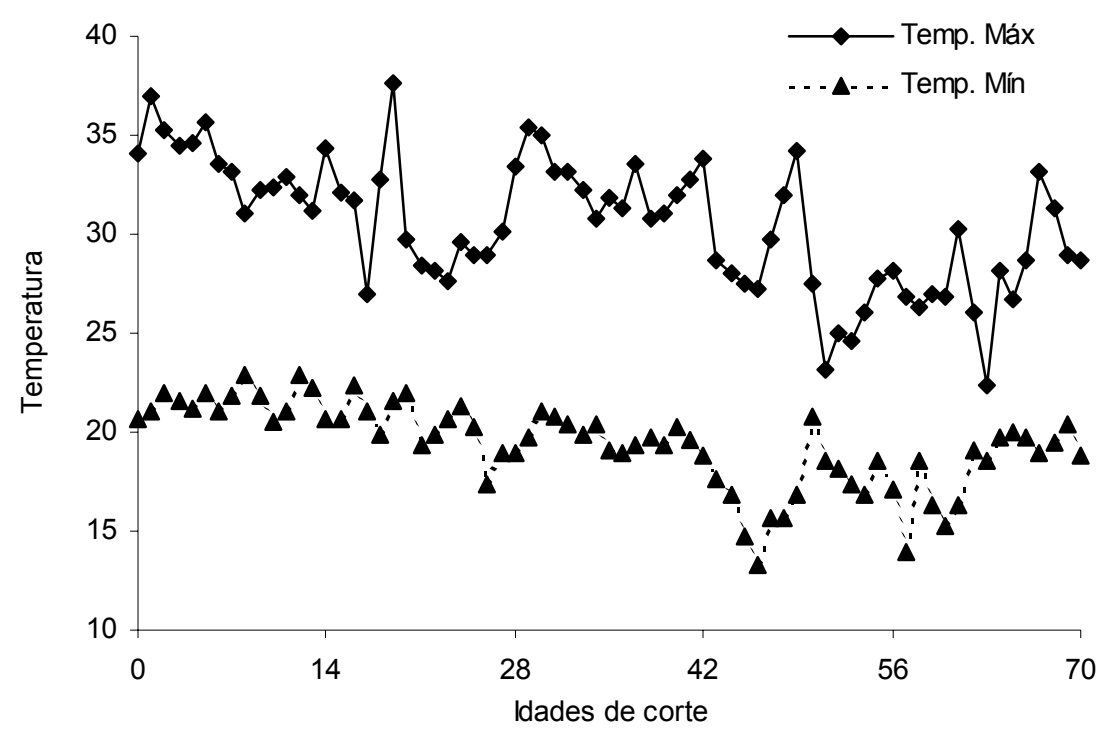

Figura 4. Temperaturas máxima e mínima às quais as gramíneas estavam expostas nas diferentes idades de corte.

\section{CONCLUSÕES}

As frações dos carboidratos das forrageiras são influenciadas pelas idades de corte, implicando elevação nos teores de carboidratos não fibrosos com o avanço da idade das plantas. $\mathrm{O}$ incremento nos níveis de adubação nitrogenada provoca redução nos teores dos carboidratos fibrosos da parede celular. Efeitos inconsistentes, contudo, são verificados sobre os teores de carboidratos não fibrosos.

\section{REFERÊNCIAS BIBLIOGRÁFICAS}

BEEVER, D.E.; MOULD, F.L. Forage evaluation for efficient ruminant livestock production. In: GIVENS, D.I.; OWEN, E.; AXFORD, R.F.E. et al. (Eds). Forage evaluation in ruminant nutrition. Wallingford: $\mathrm{CAB}$ International, 2000. p.15-41.
CAMARGOS, L.S. Análise das alterações no metabolismo do nitrogênio em Canavalia ensiformes (L.) em resposta a variações na concentração de nitrato fornecida. 2002. 44f. Dissertação (Mestrado) - Escola Superior de Agricultura Luiz de Queiroz, Universidade de São Paulo, Piracicaba, SP.

CORSI, M. Adubação nitrogenada das pastagens. In: PEIXOTO, A.M.; MOURA, J.C.; FARIA, V.P. (Eds). Pastagens: fundamentos da exploração racional. Piracicaba: FEALQ, 1994. p.155-164.

CORSI, M.; BALSALOBRE, M.A.; SANTOS, P.M. et al. Bases para o estabelecimento do manejo de pastagens de braquiária. In: SIMPÓSIO SOBRE MANEJO DE PASTAGEM, 11., 1994, Piracicaba. Anais... Piracicaba: FEALQ, 1994. p.249-266.

FOX, D.G.; SNIFFEN, C.J.; O`CONNOR, J.D. et al. A net carbohydrate and protein system for evaluating cattle diets: III. Cattle requirements 
and diet adequacy. J. Anim. Sci., v.70, p.35783596, 1992.

GARCEZ NETO, A.F.; NASCIMENTO JÚNIOR, D.; REGAZZI., A. J. et al. Respostas morfogênicas e estruturais de Panicum maximum cv. Mombaça sob diferentes níveis de adubação nitrogenada e alturas de corte. Rev. Bras. Zootec., v.31, p.1890-1900, 2002.

GOMIDE, C.A.M.; GOMIDE, J.A.; HUAMAN, C.A.M. et al. Fotossíntese, reservas orgânicas e rebrota do capim-mombaça (Panicum maximum Jacp.) sob diferentes intensidades de desfolha do perfilho principal. Rev. Bras. Zootec., v.31, p.2165-2175, 2002.

GONÇALVES, A.C. Características morfogênicas e padrões de desfolhação em pastos de capim Marandu submetidos a pastejo contínuo. 2002. 124f. Dissertação (Mestrado) Escola Superior de Agricultura Luiz de Queiroz, Universidade de São Paulo, Piracicaba, SP.

JOHNSON, R.A.; WICHERN, D.W. Applied multivariate statistical analysis. 4.ed. New Jersey: Prentice-Hall, 1998. 816p.

MERTENS, D.R. Using fiber and carbohydrate analyses to formulate dairy rations. In: INFORMATIONAL CONFERENCE WITH DAIRY AND FORAGES INDUSTRIES. 1996, Wisconsin. Proceedings... Wisconsin, 1996. p.81-92.

MESQUITA, E.E.; FONSECA, D.M.; NASCIMENTO JÚNIOR, D. et al. Efeito de métodos de estabelecimento de Brachiaria e Estilosantes e de doses de calcário, fósforo, e gesso sobre alguns componentes nutricionais da forrageira. Rev. Bras. Zootec., v.31, p.21862196, 2002.

RUSSELL, J.B.; O’CONNOR, J.D.; FOX, D.G. et al. A net carbohydrate and protein system for evaluating cattle diets: I. Ruminal fermentation. J. Anim. Sci., v.70, p.3551-3561, 1992.

SARAIVA, O.F.; CARVALHO, M.M. Adubação nitrogenada e fosfatada para $\mathrm{o}$ estabelecimento de capim-elefante em latossolo vermelho-amarelo textura argilose. Rev. Bras. Cien. Solo, v.15, p.201-205, 1991.

SBRISSIA, A.F. Compensação tamanho/densidade populacional de perfilhos em pastagem de Cynodon spp. 2000. 80f. Dissertação (Mestrado) - Escola Superior de Agricultura Luiz de Queiroz, Universidade de São Paulo, Piracicaba, SP.

SILVA, D.J.; QUEIROZ, A.C. Análises de alimentos: métodos químicos e biológicos. 3.ed. Viçosa: UFV, 2004. 235p.

SILVA, M.M.P. Características produtivas, morfogênicas e composição químicobromatológica de gramíneas forrageiras tropicais, submetidas a diferentes condições hídricas do solo. 2003. 131f. Tese (Doutorado) Universidade Estadual do Norte Fluminense, Campos dos Goytacazes, RJ.

SNIFFEN, C.J.; O`CONNOR, J.D.; VAN SOEST, P.J. et al. A net carboydrate and protein system for evaluating cattle diets: II. Carbohydrate and protein availability. J. Anim. Sci., v.70, p.3562-3577, 1992.

VAN SOEST, P.J. Nutrition ecology of the ruminant. 2.ed. Ithaca: Cornell University, 1994. 476p.

VAN SOEST, P.J.; ROBERTSON, J.B. Analysis of forages and fibrous foods. Ithaca: Cornell University, 1985. 202p.

VAN SOEST, P.J.; ROBERTSON, J.B.; LEWIS, B.A. Methods for dietary fiber, neutral detergent fiber, and nonstarch polysaccharides in relation to animal nutrition. J. Dairy Sci., v.74, p.35833597,1991 .

VITTORI, A. Produção e determinação das frações de proteínas e de carboidratos de gramíneas tropicais. 1998. 79f. Dissertação (Mestrado) - Universidade Estadual do Norte Fluminense, Campos dos Goytacazes, RJ. 